\title{
Growth of height and leg length of children in Beijing and Xilinhot, China
}

\author{
Kumi Ashizawa ${ }^{1 *}$, Noriko Tanamachi ${ }^{1}$, Sumiyo Kato ${ }^{1}$, Chiyoko KumakURA ${ }^{1}$, Xia ZHOU $^{1}$, \\ Feng $\mathrm{JIN}^{2}$, Yuling $\mathrm{LI}^{3}$, Shunhua $\mathrm{LU}^{3}$ \\ ${ }^{1}$ Institute of Human Living Sciences, Otsuma Women's University, Tokyo 102-8357, Japan \\ ${ }^{2}$ Institute of Psychology, Chinese Academy of Sciences, Beijing 100864, China \\ ${ }^{3}$ College of Life Science and Technology, Inner Mongolia Normal University, Huhehaote, Inner Mongolia, China
}

Received 30 January 2007; accepted 25 July 2007

\begin{abstract}
A number of papers on the growth of Chinese children have been published in local journals in China in the Chinese language. However, we noticed that height and weight are the main focus of these studies. Because leg length relative to height is of interest in human biology, the current study focuses on the growth of this proportion. Two groups of Chinese children were investigated: 587 boys and 625 girls in Beijing in 1997 aged 6-18 years, and 579 boys and 615 girls in Xilinhot, Inner Mongolia, in 2005 aged 7-18 years. Height and leg length (iliospinal height) were measured, and the ratio of leg length to height was calculated for each child. Mean distance curves and spline-smoothed yearly increment curves were obtained. In order to clarify the difference between the two groups of Chinese children, data from Japanese children were adopted as a control. The Beijing children were taller than the Xilinhot children, but no difference was detected in leg length between them. The ages at 'takeoff' and 'peak' obtained on the yearly increment spline-smoothed curve of height in the Xilinhot children boys were 1.2-1.8 years earlier, respectively, than those of the Beijing boys. In the girls, these two ages were almost the same in the two cities, although the 'peak' was $1.8 \mathrm{~cm}$ greater in the Xilinhot girls. Leg length in the boys was almost the same in both Beijing and Xilinhot. In the girls of the Xilinhot group, leg length was greater after puberty. Consequently, the ratio of leg length to height was greater in the Xilinhot children than the Beijing children. It is suggested, in China, that socioeconomic factors influence growth of height to a greater extent than growth of leg length, and that leg length and leg length relative to height might be controlled by a genetic factor.
\end{abstract}

Key words: Height, relative leg length, children, Beijing, Inner Mongolia

\section{Introduction}

Although many studies of the growth of children in mainland China have been published, these have been restricted to local journals in the Chinese language; from an international perspective, very few studies are available, at least in the last two decades. In this Chinese literature we have noticed that the growth of height and weight is the major interest of Chinese researchers. Reports on percentile-standard growth curves, regional/ethnic differences, and secular change were given, always based upon Chinese National Survey data (Zhang and Huang, 1988; Lin et al., 1992; Ji et al., 1995; Ji and Ohsawa, 1996; Li et al., 1999; Bi and Ji, 2005). Apart from these reports, using data obtained from field work, Weitz et al. (2004) studied not only height and weight but also chest girth and diameter, and skinfolds in Tibetan and Han children born and raised at three different

* Correspondence to: Kumi Ashizawa, Institute of Human Living Sciences, Otsuma Women's University, 12 Sanban-cho, Chiyodaku, Tokyo 102-8357, Japan.

E-mail: akumi@otsuma.ac.jp

Published online 14 November 2007

in J-STAGE (www.jstage.jst.go.jp) DOI: 10.1537/ase.070130 high altitudes on the Qinghai-Tibetan Plateau. The authors concluded that there were no differences in general growth between the two groups, although both groups grew more slowly than urban children living at low altitude in China, and the Tibetans of both sexes possessed significantly larger chests. The Tibetans' large thorax was attributed by the authors to the response to hypoxia during growth. Concerning leg length (iliospinal height), no Chinese references are available to our knowledge.

However, leg length is a very interesting subject in human biology for three reasons. First, this measurement reflects the so-called 'racial' or genetic difference: contrast the long legs of Africans with the short legs of Mongoloids. For example, the standard deviation (SD) score of two West African populations of adults compared with a group of Japanese students was almost 0 for height, whereas for iliospinal height it was +1 SD for Yoruba and +2 SD for BambaraFulbe in both sexes (Ashizawa et al., 1994). Such differences are possibly related to differentiation of the so-called 'race' during human population dispersals, and are classically interpreted following Allen's rule (Allen, 1877). The latter can be very briefly summarized as follows: a homeothermic animal living in a hot climate has a smaller body volume-to-surface ratio, and vice versa, as a result of ther- 
mal adaptation. Much more briefly it holds that animals adapted to cold have shorter limbs and protruding body parts. Schreider (1971) noted the geographic distributions of weight/surface ratio and limb-length/weight ratio in Africa, and remarked that the former decreased in warm climates, whereas the latter increased. The author concluded that these geographical differences might be considered as ecological gradients related to body-heat regulation.

Second, shorter persons have shorter legs relative to height, as shown by mean values of males and females in a genetically homogeneous group (Olivier, 1965). Comparing Japanese males and females of the same range of height $(170-179 \mathrm{~cm})$, Kato et al. (1989) confirmed that the leg (iliospinal height) was longer in the females.

Third, height and leg length are sensitive indicators of the socioeconomic or nutritional environment, as was observed in the secular trend in Japanese children after World War II (Tanner et al., 1982; Ashizawa, 2002), in Hong Kong-Chinese children between 1963 and 1993 (Leung et al., 1996), and in the difference between the Maya in Guatemala and Mayan Americans in the USA (Bogin et al., 2002). However, not many reports have been carried out from this point of view, i.e. comparison between or among genetically identical groups. On the other hand comparisons between genetically different populations have been made in two references: Oaxaca children in Mexico and North American children (Buschang et al., 1986), and well-off Indian children and the British standard (Pathmanathan and Prakash, 1994). However, in these studies it is not possible to discuss the origin of the differences, since both genetic and environmental factors are quite heterogeneous between the populations compared.

In the course of our cross-sectional growth study in Beijing and Xilinhot, Inner Mongolia, the difference in linear proportion of the body between these two groups attracted our interest. We therefore carried out this study to find out to what extent and why this difference existed between populations so close geographically and genetically.

\section{Subjects}

The following two groups of Chinese children were studied.

\section{Children in Beijing}

This group consisted of 587 boys and 625 girls, aged 6-18 years, attending elementary and high schools in Beijing. The children were measured in 1997. The area where they lived was Chaoyang, in the northern part of the city, near the peripheral highway. Until the middle 1970 s, this area was a remote agricultural region, but it is now incorporated into the city. More than $95 \%$ of the children were born in Beijing, and ethnically $92.5 \%$ were Han. Forty-five percent of the fathers were manual laborers and $15 \%$ were office-workers; $37 \%$ of the mothers were office-workers and $29 \%$ were manual laborers; $1.3 \%$ of the fathers and $2.4 \%$ of the mothers were farmers. The children were the same subjects whose TW3 skeletal maturation of the hand and wrist has been reported on by Ashizawa et al. (2005).

In comparison with the standard growth curves of chil- dren in Beijing obtained from the national data of 1995 (Li et al., 1999), the mean height of the subject children of this study was between the 50th and 75th percentile curves until age 11 in the boys and until age 9 in the girls; after these ages the mean height of the subjects children decreased in both sexes into the 20th and 50th percentile curves. In brief, the Beijing children in this study were slightly taller than the Beijing standard, but nevertheless can be considered as a representative group of this city.

\section{Children in Xilinhot}

This group consisted of 579 boys and 615 girls, aged 7-18 years, attending elementary and high schools in Xilinhot, Inner Mongolia, China. The children were measured in 2005. Fifty-one percent of the children were born in Xilinhot, and $49 \%$ outside of the city, but all within Inner Mongolia. Ethnically $99.8 \%$ of the children were Mongolian and $0.2 \%$ were Han. Among their parents, $99.2 \%$ of the fathers and $99.8 \%$ of the mothers were Mongolian, and the rest were Han. Their basic occupation is stock-farming of sheep; $79 \%$ of the fathers and $83 \%$ of the mothers were nomads, followed by $12 \%$ and $7 \%$ as public servants, respectively; $3 \%$ of the parents' occupations were categorized as 'other', which included drivers, doctors, farmers, manual laborers, policemen, and technicians. The children from nomadic families living in the grassland were boarding at school.

Geographically, Beijing is situated at $40^{\circ} \mathrm{N}$ latitude and Xilinhot at $44^{\circ} \mathrm{N}$ latitude; both are at longitude $116^{\circ} \mathrm{E}$. The two regions are situated about $450 \mathrm{~km}$ apart (straight distance, or $640 \mathrm{~km}$ by road).

The mean minimum temperature in Beijing is $-10^{\circ} \mathrm{C}$ in January and the mean maximum temperature is $31^{\circ} \mathrm{C}$ in July. In contrast, Xilinhot is known as the coldest place in northern China: $-20^{\circ} \mathrm{C}$ in January and $21^{\circ} \mathrm{C}$ in July; extremes of temperature there have been recorded at $-42.4^{\circ} \mathrm{C}$ and $39.9^{\circ} \mathrm{C}$, respectively. Inner Mongolia is also characterized by extremely dry weather throughout the year: $64-73 \%$ of the days in a year are sunny. Therefore, a great part of the land is covered with desert and grass.

These two cities, Beijing and Xilinhot, contrast with each other socioeconomically: the former is the capital and one of the most economically developed regions in China, whereas the latter is in a remote area where the economic development falls far behind that of the areas along the mainland Chinese coast and Beijing.

To make clear the contrast between the physical features of the two groups of children, we adopted Japanese data from children aged 6-12 years in Tokyo and Zinego, Akita Prefecture (Ashizawa et al., 1993), and on children aged 1318 years in Tokyo (Kusumoto, 1993). In the younger group, no regional difference was detected by the $t$-test for height and weight and by the non-parametric test (Mann-Whitney test) for the ratio of leg length to height in all age groups in both sexes. Therefore, we consolidated the Tokyo and $\mathrm{Zi}$ nego groups as a single Japanese group. We referenced these old data sets out of necessity: first, there are no data sets of normal Japanese children measured not only for height and weight but also for leg length and skinfolds; secondly, the acceleration of growth in Japanese children seems to have come to a virtual halt during the past two decades: from 
1985 to 2004, for example, boys of age 5 had gained only $3 \mathrm{~mm}$ in height and $0 \mathrm{~kg}$ in weight, boys of age 17 had gained $6 \mathrm{~mm}$ and $2 \mathrm{~kg}$; girls of age 5 had gained $2 \mathrm{~mm}$ and $0 \mathrm{~kg}$ and girls of age $17 \mathrm{had}$ gained $3 \mathrm{~mm}$ and $0.7 \mathrm{~kg}$.

\section{Methods}

Decimal age was obtained for each child based on the examination date and his/her birth date according to the International Biological Programme (Weiner and Lourie, 1981). The 'age 10' age group, for example, is composed of children between age 9.50 to age 10.49 , and is indicated in Table 1 as ' $10 \pm$ '.

Height and left leg length (iliospinal height) were measured by two experts $\mathrm{K}$ and $\mathrm{T}$ among the authors in Beijing and Xilinhot, respectively. Any children having more or fewer than \pm 3 SD values for one of the measurements in each age group and each sex were excluded from the data. With the new data sets thus obtained, the following statistical procedure was executed.

Using height and leg length, the ratio of leg length to height (leg length/height $\times 100$ ) of each child was calculated. The distribution pattern was then examined in each age group of each sex in Beijing and Xilinhot, respectively. When more than one-thirds of the age groups among the total number of age groups was detected to be non-normal for a measurement, the distribution pattern of this measurement as a whole was considered as non-normal; only the leg length-to-height ratio in both Beijing and Xilinhot was confirmed as non-normal. Therefore, the $t$-test was used to examine the statistical difference for height and leg length, whereas the nonparametric test (Mann-Whitney test) was used for the leg length-to-height ratio.

The Statistical Package for Social Sciences (SPSS), version 10 for Macintosh, was used for statistical analysis, and the cubic spline analysis package was applied for calculating the growth curve parameters (Spline Smoothing Analysis, version 2, Nippon IMSL Co. Ltd., Japan).

\section{Results}

The mean and SD values of height, leg length, and leg length-to-height ratio are given in Table 1. As the difference between mean and median of leg length-to-height was extremely small ( 0 in $17,0.1$ in 24 , and 0.2 in 9 among total 50 age groups), the mean and SD, not median, are provided. Table 2 gives the biological variables obtained from the cubic spline analysis on the yearly increment curve, based on the mean values of cross-sectional data.

The mean height curve and pattern in yearly increments smoothed by cubic spline analysis of the children in Beijing and Xilinhot are given in Figure 1a. The children in Beijing were taller than those in Xilinhot in both sexes, except at ages 12,13 , and 18 years in the boys, and ages $12-14,17$, and 18 years in the girls. Superimposing the mean growth curves of the Japanese children on those of the Beijing and Xilinhot children shows that the height of the Japanese boys was almost the same as that of Xilinhot boys before puberty, whereas after puberty the Japanese height curve comes close to the Beijing height curve. In contrast, the Japanese girls' height was almost the same as that of Xilinhot girls throughout, from 7 to 18 years of age.

The curves in the lower part of the Figure 1a represent yearly increments of the mean values but not the velocities, since the data were cross-sectional. However, in the following description, we replace the term 'maximum yearly increment between paired age groups' with the term 'peak', and replace 'preadolescent minimum yearly increment between paired age groups' with 'take-off' in order to simplify the description. On the height increment curves of the boys, the increments at 'take-off' and 'peak' were almost the same respectively in Beijing, Xilinhot, and Japan, but the ages at 'peak' were 1.2 and 1.8 years earlier, respectively, in the Xilinhot boys than in the Beijing and Japanese boys. In the girls, however, the height increment curves showed a different pattern from those of the boys, i.e. the ages at 'take-off' and 'peak' were almost the same in the three groups, but in contrast to the boys, the 'peak' was $1.8 \mathrm{~cm}$ greater in the Xilinhot girls than in the Beijing and Japanese girls. Concerning these increment curves, we note an interesting phenomenon: at ages 17 and 18 in both sexes, the Japanese children continued to grow while height increment in the Xilinhot and especially in the Beijing children fell to zero, or even to minus zero. This suggests the attainment of adult height occurred earlier in the Chinese than in the Japanese.

Mean leg length and the pattern of yearly increment curves are given in Figure 1b. For the leg length, almost no significant differences were detected between the Xilinhot and Beijing children, especially in the boys, and only sometimes detected in the girls after puberty. Rather, a reverse tendency to that which we noticed in height could be observed, i.e. the leg length of the Xilinhot children was rather greater than that of the Beijing children after puberty. The Japanese children's leg length was very close to that of the Beijing children in both sexes, except in boys at 17 and 18 years of age.

On the leg length increment curves, we noticed that the 'peak' in the Beijing children was less accentuated than that of the Xilinhot children in both the boys and the girls. The age at 'peak' of the Xilinhot boys was 1.2 years ahead of that in the Beijing boys (age 11.2 in the former and age 12.4 in the latter), whereas this age was almost the same in the girls (ages 10.5 and 10.8, respectively). Based on these increment curves, we note that the ages at 'peak' of height and leg length were almost the same in both Beijing and Xilinhot in both sexes. But comparing the percentage of leg length elongation to height augmentation at 'peak', the percentage observed in the Xilinhot boys was the greatest, $70 \%$, while that in the Beijing boys was 54\%, and in the Beijing and Xilinhot girls the percentages were $57 \%$ and $58 \%$, respectively. The increment curve of the Japanese boys was quite close to that of the Beijing boys, while that of the Japanese girls was intermediate between those of the Beijing and Xilinhot girls. A feature of the Japanese children that should be noted is that their legs continued to elongate even at 17 and 18 years of age, showing positive yearly increments in contrast to the zero increment of the Xilinhot and the negative increment of the Beijing children in both sexes. 
Table 1. Mean and standard deviation (SD) values of height, leg length, and leg length-to-height ratio in the children from Beijing and Xilinhot

\begin{tabular}{|c|c|c|c|c|c|c|c|c|c|c|c|c|c|}
\hline & \multirow{3}{*}{ Age groups } & \multicolumn{6}{|c|}{ Beijing } & \multicolumn{6}{|c|}{ Xilinhot } \\
\hline & & \multicolumn{3}{|c|}{ Boys } & \multicolumn{3}{|c|}{ Girls } & \multicolumn{3}{|c|}{ Boys } & \multicolumn{3}{|c|}{ Girls } \\
\hline & & $n$ & Mean & SD & $n$ & Mean & $\mathrm{SD}$ & $n$ & Mean & $\mathrm{SD}$ & $n$ & Mean & SD \\
\hline \multirow[t]{12}{*}{ Age, years } & $6 \pm$ & 13 & 6.29 & 0.15 & 13 & 6.21 & 0.18 & - & - & - & - & - & - \\
\hline & $7 \pm$ & 53 & 6.99 & 0.26 & 50 & 6.99 & 0.29 & 38 & 7.16 & 0.22 & 38 & 7.18 & 0.18 \\
\hline & $8 \pm$ & 45 & 8.01 & 0.27 & 52 & 8.02 & 0.27 & 45 & 7.97 & 0.30 & 45 & 8.02 & 0.31 \\
\hline & $9 \pm$ & 50 & 9.02 & 0.29 & 53 & 9.02 & 0.29 & 43 & 9.00 & 0.26 & 43 & 8.96 & 0.28 \\
\hline & $11 \pm$ & 43 & 11.03 & 0.31 & 63 & 10.99 & 0.28 & 55 & 11.01 & 0.27 & 55 & 11.00 & 0.32 \\
\hline & $12 \pm$ & 41 & 11.90 & 0.27 & 53 & 11.88 & 0.28 & 54 & 11.99 & 0.30 & 54 & 12.02 & 0.27 \\
\hline & $13 \pm$ & 47 & 13.02 & 0.27 & 48 & 13.00 & 0.27 & 54 & 13.00 & 0.27 & 54 & 13.06 & 0.28 \\
\hline & $14 \pm$ & 60 & 13.97 & 0.31 & 45 & 13.96 & 0.30 & 51 & 13.98 & 0.26 & 51 & 14.01 & 0.31 \\
\hline & $15 \pm$ & 61 & 15.00 & 0.30 & 63 & 14.94 & 0.29 & 44 & 14.95 & 0.28 & 44 & 14.92 & 0.30 \\
\hline & $16 \pm$ & 44 & 15.99 & 0.30 & 43 & 15.97 & 0.31 & 55 & 15.97 & 0.27 & 55 & 15.97 & 0.31 \\
\hline & $17 \pm$ & 50 & 16.99 & 0.29 & 53 & 17.01 & 0.31 & 47 & 16.99 & 0.27 & 47 & 17.01 & 0.29 \\
\hline & $18 \pm$ & 32 & 17.86 & 0.26 & 45 & 17.88 & 0.27 & 50 & 17.97 & 0.29 & 50 & 18.01 & 0.28 \\
\hline \multirow{12}{*}{ Height, cm } & $7 \pm$ & 53 & 122.1 & 5.21 & 50 & 122.2 & 5.55 & 38 & 119.7 & 4.80 & 36 & 117.4 & 5.31 \\
\hline & $8 \pm$ & 45 & 129.2 & 3.71 & 52 & 128.3 & 4.93 & 45 & 123.5 & 5.28 & 45 & 123.2 & 6.15 \\
\hline & $9 \pm$ & 50 & 133.9 & 4.90 & 53 & 133.0 & 5.81 & 43 & 129.3 & 5.70 & 55 & 129.0 & 5.76 \\
\hline & $10 \pm$ & 48 & 138.8 & 5.07 & 44 & 138.5 & 6.89 & 43 & 133.8 & 6.52 & 52 & 133.9 & 5.72 \\
\hline & $11 \pm$ & 43 & 143.4 & 4.85 & 63 & 145.0 & 7.12 & 55 & 138.6 & 6.22 & 51 & 142.1 & 7.56 \\
\hline & $12 \pm$ & 41 & 147.8 & 8.20 & 53 & 150.2 & 5.10 & 54 & 145.7 & 6.48 & 60 & 150.5 & 5.36 \\
\hline & $13 \pm$ & 47 & 155.1 & 8.67 & 48 & 155.2 & 5.59 & 54 & 154.5 & 7.76 & 47 & 153.3 & 5.93 \\
\hline & $14 \pm$ & 60 & 162.5 & 8.35 & 45 & 156.5 & 4.88 & 51 & 155.6 & 8.87 & 48 & 155.2 & 4.67 \\
\hline & $15 \pm$ & 61 & 166.1 & 6.94 & 63 & 158.0 & 6.07 & 44 & 162.7 & 6.95 & 48 & 155.9 & 4.21 \\
\hline & $16 \pm$ & 44 & 170.2 & 5.03 & 43 & 159.1 & 5.38 & 55 & 166.1 & 6.96 & 66 & 156.9 & 4.55 \\
\hline & $17 \pm$ & 50 & 172.1 & 5.19 & 53 & 159.1 & 5.81 & 47 & 168.8 & 6.33 & 52 & 157.3 & 4.67 \\
\hline & $18 \pm$ & 32 & 170.3 & 4.72 & 45 & 158.3 & 4.46 & 50 & 168.2 & 5.34 & 55 & 157.5 & 4.63 \\
\hline \multirow{10}{*}{$\begin{array}{l}\text { Leg length, } \\
\mathrm{cm} \text {, left }\end{array}$} & $6 \pm$ & 13 & 60.1 & 2.37 & 13 & 59.5 & 2.42 & - & - & - & - & - & - \\
\hline & $7 \pm$ & 53 & 64.1 & 3.33 & 50 & 64.4 & 3.77 & 38 & 65.0 & 3.28 & 36 & 64.3 & 3.61 \\
\hline & $8 \pm$ & 45 & 68.7 & 2.50 & 52 & 68.5 & 3.39 & 45 & 68.0 & 3.73 & 45 & 67.9 & 4.19 \\
\hline & $12 \pm$ & 41 & 81.6 & 5.55 & 53 & 82.1 & 3.40 & 54 & 82.7 & 4.17 & 60 & 85.1 & 3.51 \\
\hline & $13 \pm$ & 47 & 85.4 & 5.40 & 48 & 84.7 & 3.91 & 54 & 88.0 & 5.44 & 47 & 86.1 & 3.71 \\
\hline & $14 \pm$ & 60 & 89.5 & 5.36 & 45 & 84.8 & 3.73 & 51 & 88.0 & 5.24 & 48 & 86.7 & 2.84 \\
\hline & $15 \pm$ & 61 & 90.5 & 4.35 & 63 & 85.6 & 4.43 & 44 & 91.1 & 3.90 & 48 & 86.4 & 2.92 \\
\hline & $16 \pm$ & 44 & 92.3 & 3.23 & 43 & 85.8 & 3.71 & 55 & 92.7 & 4.57 & 66 & 86.5 & 3.22 \\
\hline & $17 \pm$ & 50 & 92.7 & 4.02 & 53 & 85.6 & 4.43 & 47 & 94.3 & 4.23 & 52 & 87.8 & 4.15 \\
\hline & $18 \pm$ & 32 & 91.6 & 3.49 & 45 & 85.3 & 3.32 & 50 & 94.0 & 3.60 & 55 & 87.4 & 3.49 \\
\hline \multirow{13}{*}{$\begin{array}{l}\text { Leg length- } \\
\text { to-height ratio }\end{array}$} & $6 \pm$ & 13 & 51.5 & 0.85 & 13 & 51.3 & 0.89 & - & - & - & - & - & - \\
\hline & $7 \pm$ & 53 & 52.5 & 1.02 & 50 & 52.7 & 1.11 & 38 & 54.3 & 1.32 & 36 & 54.8 & 1.16 \\
\hline & $8 \pm$ & 45 & 53.2 & 0.98 & 52 & 53.3 & 1.13 & 45 & 55.1 & 1.13 & 45 & 55.1 & 1.13 \\
\hline & $9 \pm$ & 50 & 53.4 & 1.26 & 53 & 54.0 & 1.29 & 43 & 55.7 & 1.15 & 55 & 56.1 & 1.17 \\
\hline & $10 \pm$ & 48 & 54.2 & 1.04 & 44 & 54.5 & 0.97 & 43 & 55.6 & 1.14 & 52 & 56.4 & 1.23 \\
\hline & $11 \pm$ & 43 & 54.7 & 0.98 & 63 & 54.5 & 1.00 & 55 & 56.3 & 1.13 & 51 & 56.6 & 1.20 \\
\hline & $12 \pm$ & 41 & 55.1 & 1.09 & 53 & 54.6 & 1.12 & 54 & 56.8 & 1.08 & 60 & 56.6 & 0.98 \\
\hline & $13 \pm$ & 47 & 55.1 & 0.92 & 48 & 54.6 & 1.27 & 54 & 57.0 & 1.28 & 47 & 56.1 & 1.33 \\
\hline & $14 \pm$ & 60 & 55.0 & 1.16 & 45 & 54.2 & 1.27 & 51 & 56.6 & 1.15 & 48 & 55.9 & 1.14 \\
\hline & $15 \pm$ & 61 & 54.5 & 1.30 & 63 & 54.1 & 1.28 & 44 & 56.0 & 1.28 & 48 & 55.4 & 1.05 \\
\hline & $16 \pm$ & 44 & 54.2 & 0.96 & 43 & 53.9 & 1.18 & 55 & 55.8 & 1.38 & 66 & 55.1 & 1.01 \\
\hline & $17 \pm$ & 50 & 53.8 & 1.24 & 53 & 53.8 & 1.25 & 47 & 55.9 & 1.17 & 52 & 55.8 & 1.65 \\
\hline & $18 \pm$ & 32 & 53.8 & 1.28 & 45 & 53.9 & 1.16 & 50 & 55.9 & 1.27 & 55 & 55.5 & 1.24 \\
\hline
\end{tabular}

\section{Discussion}

\section{Height and leg length}

Secular change in height of children in $12-17$ cities in China from the 1950s to 1985 was reported successively by five groups of authors based on presumably the same nation- al survey reports (Zhang and Huang, 1988; Lin et al., 1992; Ji et al., 1995; Ji and Ohsawa, 1996; Li et al., 1999). Separating out the data of Shandong Province from these national data, Bi and Ji (2005) found a increase of height in this province just as in the cities, and the authors concluded this might reflect secular changes in the socioeconomic status of the 
Table 2. Variables of yearly increment in height, leg length, and leg length-to-height ratio

\begin{tabular}{|c|c|c|c|c|c|}
\hline & & & Height $(\mathrm{cm})$ & Leg length $(\mathrm{cm})$ & Leg length-to-height ratio \\
\hline \multirow[t]{12}{*}{ Beijing } & Boys & Take-off & 4.4 & 3.2 & 0.4 \\
\hline & & Age at take-off (years) & 10.1 & 9.2 & 8.4 \\
\hline & & Value at 'take-off' & 139.3 & 72.4 & 53.3 \\
\hline & & Peak & 6.9 & 3.8 & 0.7 \\
\hline & & Age at peak (years) & 13.0 & 12.4 & 10.3 \\
\hline & & Value at peak & 155.1 & 83.3 & 54.3 \\
\hline & Girls & Take-off & 4.7 & 3.4 & 0.6 \\
\hline & & Age at take-off (years) & 8.7 & 8.7 & 7.9 \\
\hline & & Value at 'take-off' & 131.7 & 70.9 & 53.3 \\
\hline & & Peak & 6.9 & 3.9 & 0.6 \\
\hline & & Age at peak (years) & 10.8 & 10.5 & 8.7 \\
\hline & & Value at peak & 143.6 & 77.4 & 53.8 \\
\hline \multirow[t]{12}{*}{ Xilinhot } & Boys & Take-off & 4.0 & 2.3 & 0.1 \\
\hline & & Age at take-off (years) & 8.9 & 9.0 & 9.2 \\
\hline & & Value at 'take-off' & 128.0 & 71.4 & 55.6 \\
\hline & & Peak & 7.0 & 4.9 & 0.7 \\
\hline & & Age at peak (years) & 11.2 & 11.2 & 11.0 \\
\hline & & Value at peak & 141.2 & 79.4 & 56.3 \\
\hline & Girls & Take-off & 4.7 & 3.4 & - \\
\hline & & Age at take-off (years) & 8.9 & 8.9 & - \\
\hline & & Value at 'take-off' & 128.0 & 71.7 & - \\
\hline & & Peak & 8.7 & 5.0 & 0.7 \\
\hline & & Age at peak (years) & 10.9 & 10.8 & 8.4 \\
\hline & & Value at peak & 141.7 & 79.5 & 55.5 \\
\hline
\end{tabular}

'Take-off' and 'peak' indicate minimum and maximum yearly increments, respectively.

province.

We describe in the Results section above that the children in Beijing were taller than those in Xilinhot. Taking account of the 8 year difference of examination dates between these two cities and the increase in height during these years matching the explosive development of the economy in Beijing, this regional difference in height would certainly become greater if we could have carried out our measurements in 2005, the same year as the examination in Xilinhot. However, we cannot give a similar account for leg length as was given for height. This is because the height increase in Japanese children resulted from leg elongation, as Tanner et al. (1982) indicated, and the same effect has been observed in Hong Kong and mainland China ( $\mathrm{Li}$ et al. 1999; Zhang and Huang, 1988). But this phenomenon does not persist in the Japanese case. Since the 1980s in Japan, leg length has no longer changed, particularly in boys, whereas height increase continues, although at a slower pace; finally, the Japanese have reverted to their original leg length for height (Ashizawa, 2002). Unfortunately we have not found any discussion of leg length or sitting height in the reports of Hong Kong and China cited above.

\section{Relative leg length}

If the subject children in Beijing continue to exhibit elongation of their legs in conjunction with the positive secular change of height growth even after the year of their examination in 1997 up to the present day, we can suppose that the ratio of leg length to height has not changed much. But if their leg elongation stops although their height continues to increase, such as is the case of recent Japanese children, their leg length-to-height ratio will decrease and the relative shortness of their legs will contrast more with the children in Xilinhot because of the increasing difference of height between these locations.

The mean leg length-to-height ratio and its pattern of yearly increment of the subject children are given in Figure $2 \mathrm{a}$ and Figure $2 \mathrm{~b}$. As a consequence of the height and leg length growth, this ratio was $1.6-2.1 \%$ smaller in the Beijing children in both sexes throughout from ages 7 to 18 (Figure 2a). Before obtaining this result, we presumed that the Mongolians had shorter legs than the Han, since the former lived in a colder environment than the latter. In fact, the Xilinhot-Mongolian children, although living in a colder environment, had longer legs in both absolute and relative senses, whereas the Beijing-Han children had a longer trunk (subtracting leg length from height). The present-day lifestyles of the Beijing-Han and the Xilinhot-Mongolians contrast with each other, as we have noted above. At present, we cannot confirm that this regional/population difference is attributable to socioeconomic factors in the places where the subjects live or to genetic factors involved in each population since the time of population differentiation in so-called Mongoloid people. The children in Japan were intermediate between those in Beijing and Xilinhot.

The pattern of yearly increment curves of leg length-toheight ratio was different between the two Chinese groups in both sexes (Figure 2b). The Xilinhot children showed two 'peaks': one during puberty and a smaller one after puberty, at ages 11.0 and 17.3 years in the boys and 8.4 and 17.0 years in the girls. In contrast, the Beijing children had only one 'peak'. Moreover, the yearly increments of this ratio, es- 

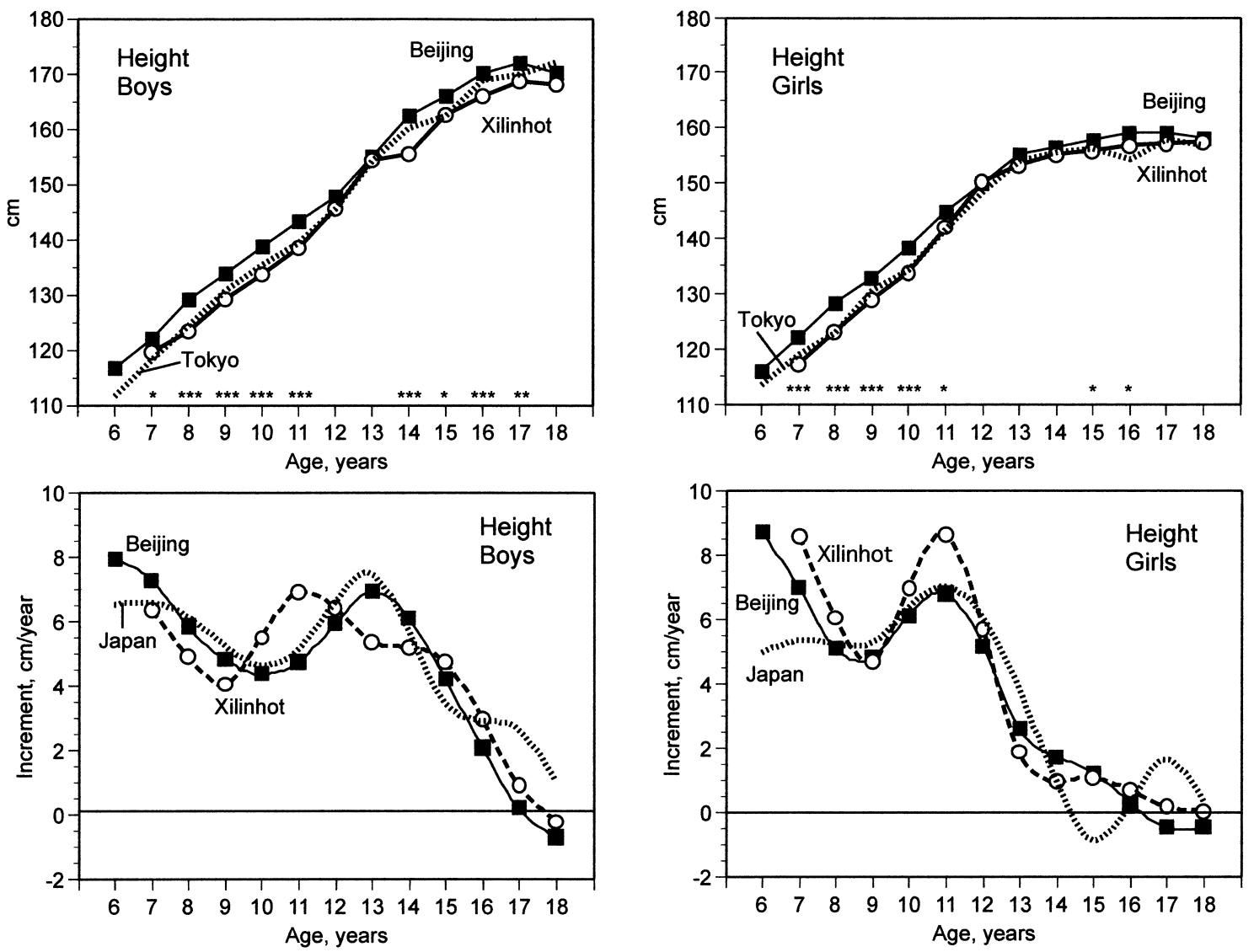

Figure 1a. Mean height curves and the yearly increments curves of the children in Beijing and Xilinhot compared with the curves of Japanese children. The asterisks in the mean curves show the significance of the difference between Beijing and Xilinhot: $* P<0.05, * * P<0.01, * * *$ $P<0.001$.

pecially in the boys, were always greater in the Xilinhot group than the Beijing group after the 'peak'. It is possible that this fact has led to the longer legs relative to height in the Xilinhot boys. As for the girls as well, the greater 'peak' and the appearance of a smaller one in the Xilinhot group possibly lead to the relatively longer legs. Superimposing the increment curves of the Japanese children on those of the Beijing and Xilinhot children, we note that the boys' curves became more variable, i.e. the increment at 'peak' and the increment at drop away in the Japanese children were almost the same as in the Beijing children, but earlier, at 0.7 and 1.7 years, respectively. As for the girls, the increment curves of the three cities coincided relatively well, although the increment at 'peak' of the Japanese girls was larger than that of the Chinese girls.

Tanner et al. (1982) pointed out that the positive secular change of height in Japanese children had originated in the progressive elongation of leg length, obtained by subtracting sitting height from height, based on the data published in the annual reports of the Ministry of Education, Culture, Sports, Science and Technology. However, Ashizawa (2002) indicated, using the same Ministry reports published after the 1980s, the country-wide anthropometric data set of 1978 1981 provided by the Japanese Standards Association (1984), and that of 1992-1994 provided by the Research In- stitute of Human Engineering for Quality Life (1997), both affiliated with the Ministry of Economy, Trade and Industry, that since the 1980s no elongation of leg length had been observed although height had continued to grow, even if slightly. Moreover, this author concluded that the growth of total body size, such as height, was influenced rather easily by socioeconomic conditions, but that body proportion, such as relative leg length to height, kept its original configuration even in favorable conditions. Therefore, it will be interesting to follow the same populations in China, to see if the height of the Xilinhot-Mongolian children will catch up with that of the Beijing-Han children, whether the former will become as tall as the latter, and whether the former will retain their absolute and relative longer leg length vis-à-vis the latter. With these results, we can estimate which factors, social or genetic, function more decisively in human growth.

\section{Sex difference}

The girls' predominance of height during puberty is widely observed in both cross-sectional surveys and longitudinal surveys, and is due to the earlier acceleration of height in girls than in boys. In our study in the Philippines (Ashizawa et al., 1998), however, we noticed that the appearance of the sex difference during puberty and the greater mean values in the girls were due to something occurring differently between 

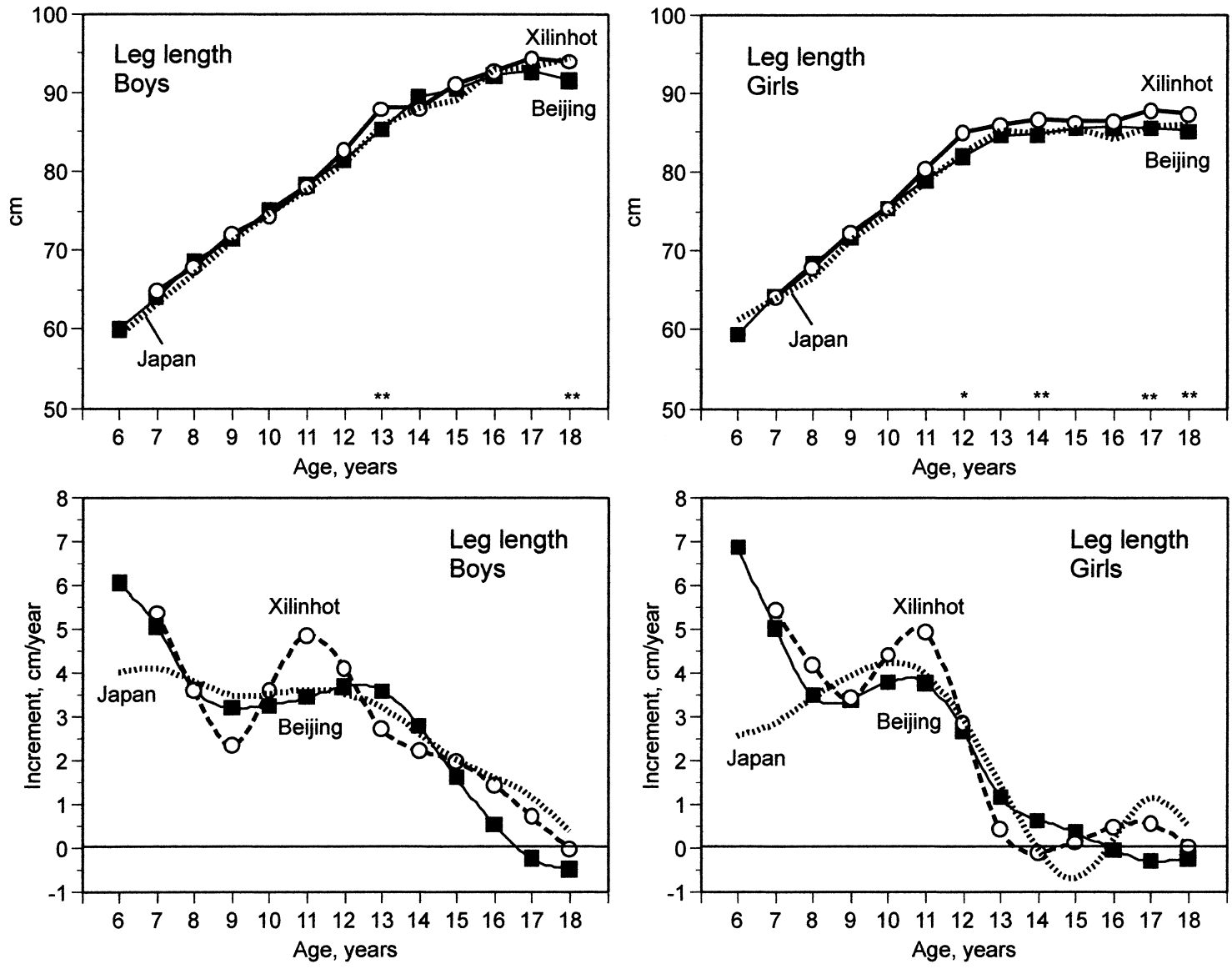

Figure 1b. Mean leg length curves and the yearly increments curves of the children in Beijing and Xilinhot compared with the curves of Japanese children. The asterisks in the mean curves show the significance of the difference between Beijing and Xilinhot: $* P<0.05, * * P<0.01, * * *$ $P<0.001$.

the group of children from well-off families and those from economically poor families. Also, comparing two groups, one in 1948 and one in 1997 in Japan (Ministry of Education, Science, Culture and Sports, 2003), the recovery of height growth after World War II was shown to be greater in girls than in boys. These phenomena suggest that the girls' height predominance during puberty was greater in an economically poor group than in a well-off group in the same region, and that height growth recovery was more rapid in the girls when socioeconomic conditions improved in the same population. In other words, a greater sensitivity in boys to a disadvantageous environment is suggested.

Figure 3a, Figure 3b, and Figure 3c give the girls' and boys' mean height, leg length, and the leg length-to-height ratio of the children in Beijing, Xilinhot, and Japan. The question marks in the figures for Japan indicate that a statistical test was not executed because of the small subject number, namely fewer than 10 .

The boys were taller than the girls after age 14 years in Beijing and after age 15 in Xilinhot, but during puberty statistically significant sex differences were detected in Xilinhot, but not in Beijing (Figure 3a). This phenomenon is possibly due to the economic differences between these two regions, and coincides well with the results in the Philip- pines mentioned above. That is to say, the boys' height growth might have been suppressed by the socioeconomic disadvantage in Xilinhot, whereas the girls' height growth seems not to have been affected, and this produced the girls' greater predominance in Xilinhot. The duration of the girls' predominance was almost the same in Beijing in 1997 and Japan in 1985. Approaching adulthood, at ages 17 and 18 years, the boys of the Chinese group ceased to grow in height, whereas the boys in Japan continued to grow.

For leg length, roughly speaking, almost the same tendency observed in height was identified; there was no significant predominance of girls noted during puberty in Beijing and Japan, whereas this predominance was remarkable in the children in Xilinhot (Figure 3b).

However, the appearance of sex dimorphism in the ratio of leg length to height was nearly the same in both the Beijing and the Xilinhot groups, i.e. greater in the girls than in the boys in early puberty, and thereafter greater in the boys (Figure 3c, upper). As for the children in Japan, no significant sex difference was detected in any of the age groups, at least which we could examine. Comparing these three groups of children in Beijing, Xilinhot, and Japan, we can see first that the children in China exhibited a greater sex dimorphism of relative leg length to height, and second that at 

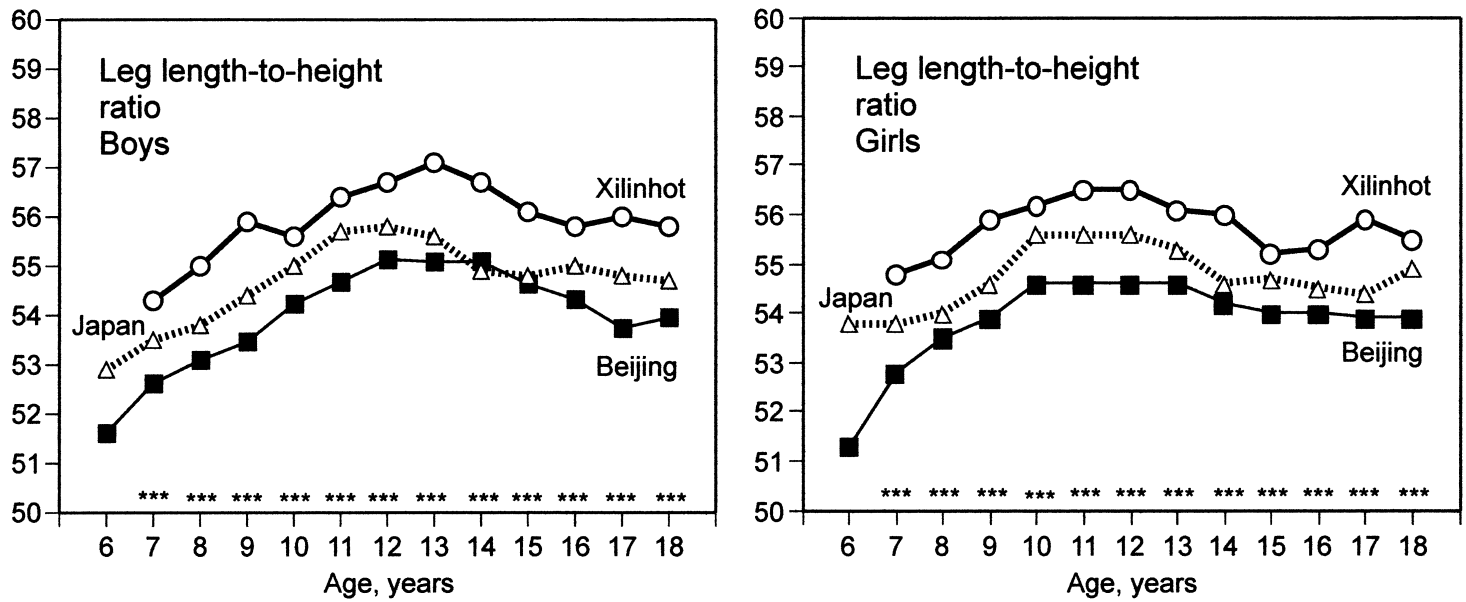

Figure 2a. Mean leg length-to-height ratio curves of the children in Beijing and Xilinhot compared with the curves of Japanese children. The asterisks in the mean curves show the significance of the difference between Beijing and Xilinhot: $* P<0.05, * * P<0.01, * * * P<0.001$.
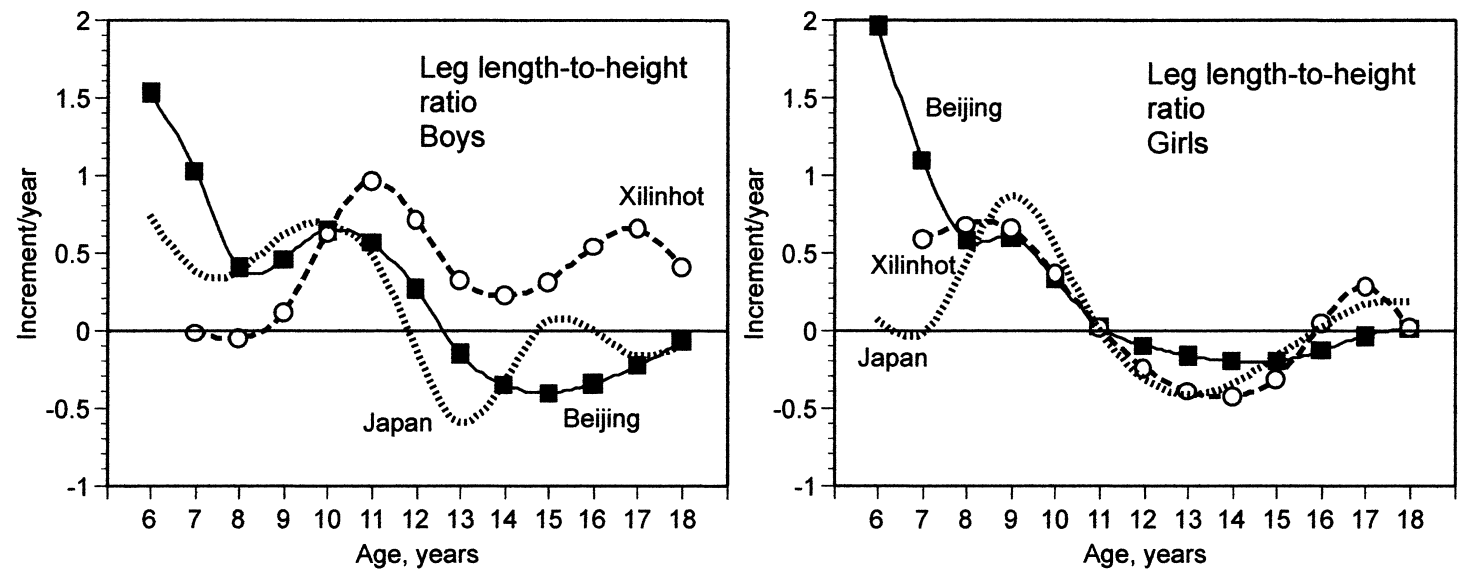

Figure 2b. Yearly increment curves of leg length-to-height ratio of the children in Beijing and Xilinhot compared with the curves of Japanese children.

the end of the growth period the boys' legs became relatively shorter than the girls' legs in Beijing and Japan, in contrast to the girls' legs in Xilinhot. It is not possible to speculate on these phenomena.

The yearly increment curves of leg length-to-height ratio indicated not only the rhythm of relative growth of leg length, but also represent a 'differential growth' of height and legs. In Figure 3c (lower), the positive ratios indicate that the tempo of leg extension exceeds that of height, and the negative ratios indicate the inverse phenomenon. Therefore, the earlier appearance of the 'peak' of this ratio in the girls (ages at 8.7, 8.4, and 9.1 years in the girls and at 10.3, 11.0, and 10.0 in the boys, in Beijing, Xilinhot, and Japan, respectively) reflected the appearance of the girls' predominance in the mean distance curve of leg length-to-height ratio from ages 8 to 10 or 11 .

\section{Conclusions}

1. The Beijing children were taller than the Xilinhot chil- dren in both sexes. Compared with the Japanese boys, the Beijing boys were taller until age 13 , but during puberty the former caught up with the latter, and the Beijing boys' mean height decreased at age 18 . The Xilinhot girls had almost the same height as the Japanese girls throughout, from 7 to 18 years of age.

2. The yearly increment curves of height were obtained from smoothing cubic spline analysis, and the ages at 'take-off' and 'peak' in the Xilinhot boys were 1.2-1.8 years earlier, respectively, than those of the Beijing and Japanese boys. In the girls, however, these two ages were almost the same in Xilinhot, Beijing, and Japan. But the 'peak' was $1.8 \mathrm{~cm}$ greater in the Xilinhot girls than that of the other two groups of girls. The spline curves suggest that the attainment of adult height was earlier in the Chinese children than in the children of Japan.

3. Leg length in the boys was almost the same in both Beijing and Xilinhot, and in the girls of the Xilinhot group it was greater after puberty. 

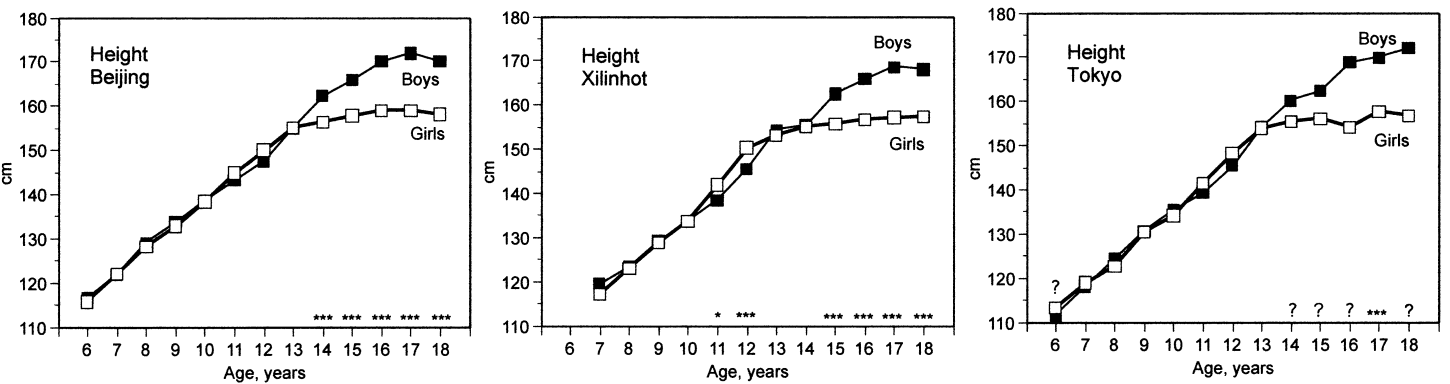

Figure 3a. Boys' and girls' mean height curves of the children in Beijing, Xilinhot, and Japan. The asterisks in the mean curves show the significance of the difference between boys and girls: $* P<0.05$, ** $P<0.01$, *** $P<0.001$. The question marks by the figure for Japan indicate that the statistical examination was not executed because of a limited sample number.
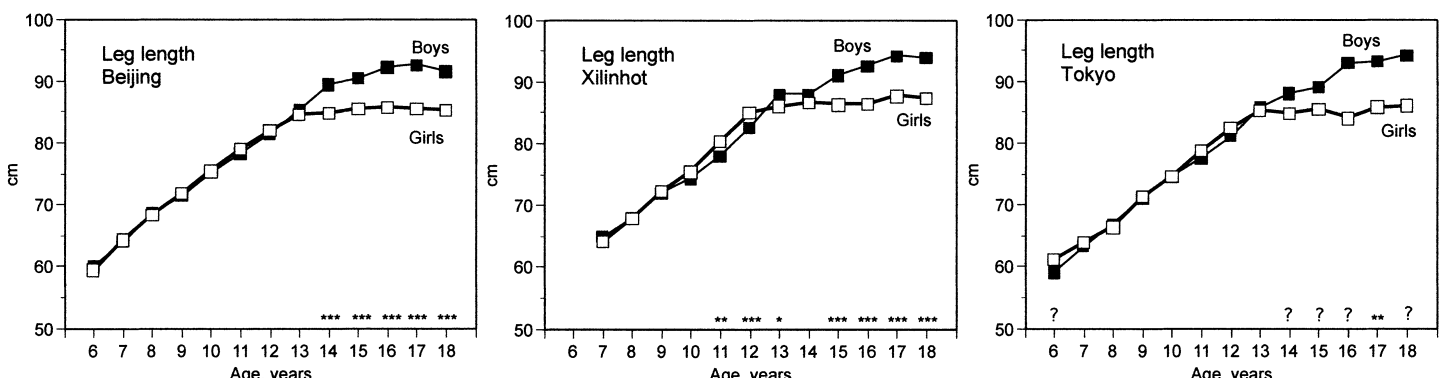

Figure 3b. Boys' and girls' mean leg length curves of the children in Beijing, Xilinhot, and Japan. The asterisks in the mean curves show the significance of the difference between boys and girls: ${ }^{*} P<0.05,{ }^{*} P<0.01, * * * P<0.001$. The question marks by the figure for Japan indicate the statistical examination was not executed because of a limited sample number.
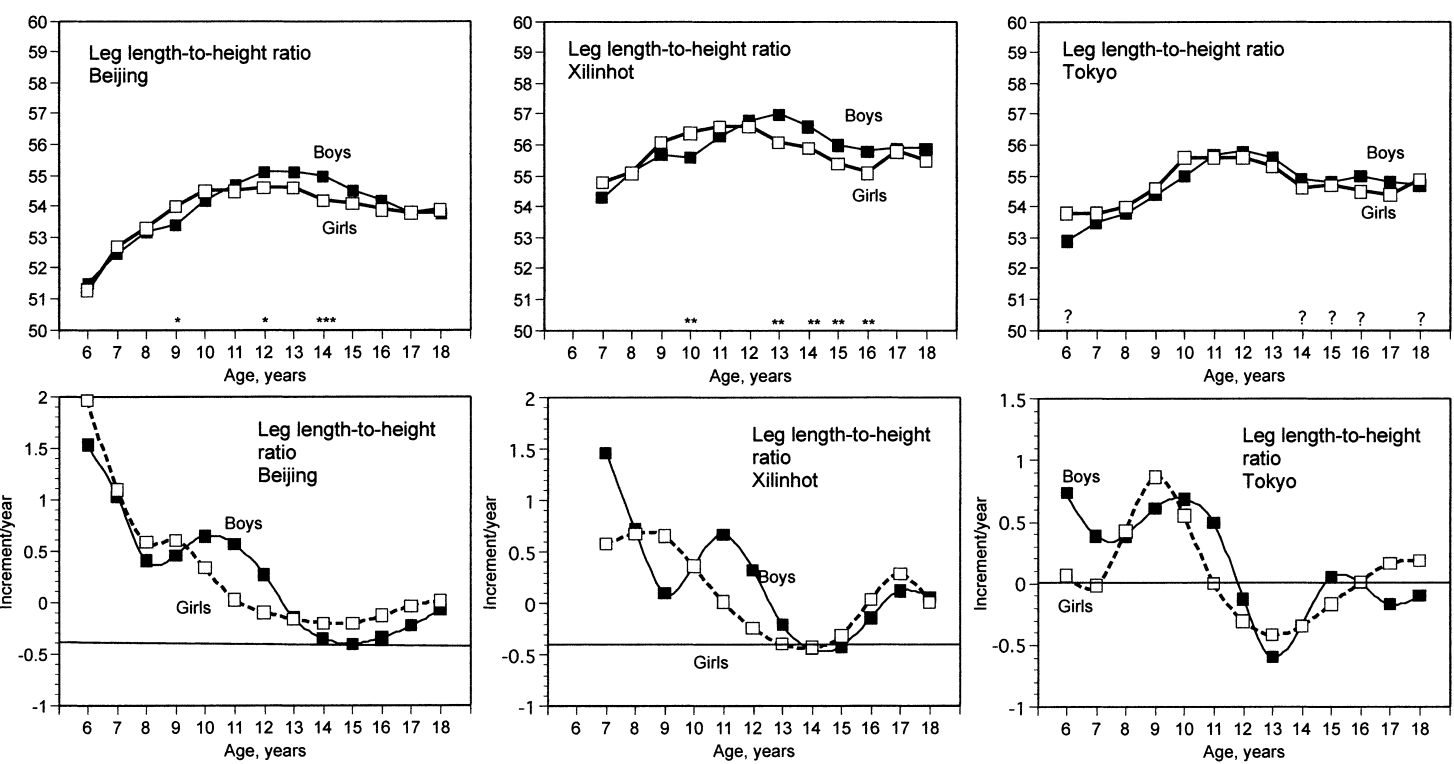

Figure 3c. Boys' and girls' mean leg length-to-height ratio curves and the yearly increment curves of the children in Beijing, Xilinhot, and Japan. The asterisks in the mean curves show the significance of the difference between boys and girls: $*<0.05, * * P<0.01, * * * P<0.001$. The question marks by the figure for Japan indicate the statistical examination was not executed because of a limited sample number.

4. As a consequence of the difference between height and leg-length growth patterns, as noted above, the leg length-to-height ratio was smaller in the Beijing children than in the Xilinhot children throughout, from 7 to 18 years of age in both sexes. This means the Beijing children had relatively shorter legs in spite of their greater height. The corresponding ratio in the Japanese children was intermediate between those of the Beijing and Xilin- 
hot children.

5. It is certain that socioeconomic factors affected the variation of height growth in the children in China. However, it is suggested that leg length and relative leg length to height might be controlled by a stronger genetic factor.

\section{Acknowledgments}

The authors wish to express their deep gratitude to the children, students, and teachers of the Elementary School and High School in Xilinhot, Inner Mongolia, for their collaboration in this study.

\section{References}

Allen J.A. (1877) The influence of physical conditions in the genesis of species. Radical Review, 1: 108-140 (available at www.wku.edu/ /smithch/biogeog/ALLE1877.htm).

Ashizawa K. (2002) Leg length increase/decrease in Japanese in the latter half of the 20th century. Anthropological Science, 110: 279-292.

Ashizawa K., Kusumoto A., Sugane A., Dobashi K., Kawabata M., and Inomata M. (1993) Anthropological data of urban and rural Japanese children. Anthropological Science, 101: 129156.

Ashizawa K., Kusumoto A., Adachi K., Hosaka M., and Kawada J. (1994) Caractères physiques des populations de cinq groupes ethniques d'Afrique de l'Ouest comparées avec des Japonais. In Boucle du Niger. Approches Multidisciplinaires. Research Institute for Languages and Culture of Asia and Africa, Tokyo University of Foreign Studies.

Ashizawa K., Kumakura C., and Kusumoto A. (1998) Growth of Philippine children in reference to socioeconomic environment. Anthropological Science, 106: 77-94.

Ashizawa K., Kumakura C., Zhou X., Jin F., and Cao J. (2005) RUS skeletal maturation of children in Beijing. Annals of Human Biology, 32: 316-325.

Bi Z. and Ji C. (2005) Secular growth changes in body height and weight in children and adolescents in Shandong, China between 1939 and 2000. Annals of Human Biology, 32: 650 665

Bogin B., Smith P., Orden A.B., Varela Silva M.I., and Loucky J. (2002) Rapid change in height and body proportions of Maya American children. American Journal of Human Biology, 14: 753-761.

Buschang P.H., Malina R.M., and Little B.B. (1986) Linear growth of Zapotec school children: growth status and yearly velocity for leg length and sitting height. Annals of Human Biology, 13: $225-234$

Japanese Standards Association (1984) Report of Japanese Body
Size for Garment Mass Production. JSA, Tokyo (in Japanese).

Ji C. and Osawa S. (1996) Changes in somatotype during growth in Chinese youth 7-18 years of age. American Journal of Human Biology, 8: 347-359.

Ji C., Osawa S., and Kasai N. (1995) Secular changes in the stature, weight, and age at maximum growth increments of urban Chinese girls from the 1950s to 1985. American Journal of Human Biology, 7: 473-484.

Kato K., Yajima T., Kouchi M., and Hoshi H. (1989) Sex difference in somatometry viewed from a comparison of similarly tall men and women. Journal of Anthropological Science of Nippon, 97: 81-93.

Kusumoto A. (1993) Ecological study of growth and foot shape of children in Japan and Isabela, Philippine. Ph. D. dissertation, Ohtsuma Women's University, Tokyo (in Japanese).

Leung S.S.F., Lau J.T. F., XU Y.Y., Tse L.Y., Huen K.F., Wong G.W.K., Law W.Y., Yeung V.T.F., Yeung W.K.Y., and Leung N.K. (1996) Secular change in standing height, sitting height and sexual maturation of Chinese - the Hong Kong growth study, 1993. Annals of Human Biology, 23: 297-306.

Li H., Leung S.S.F., Lam P.K.W., Zhang X., Chen X.X., and Wang S.L. (1999) Height and weight percentile curves of Beijing children and adolescents 0-18 years, 1995. Annals of Human Biology, 26: 457-471.

Lin W., Chen C.A.N., Su J.Z.X., Xiao J., and Ye G. (1992) Secular change in the growth and development of Han children in China. Annals of Human Biology, 19: 249-265.

Ministry of Education, Culture, Sports, Science and Technology (2003) Annual Report on School Health Survey. Government Printing Office, Tokyo (in Japanese).

Olivier G. (1965) Morphologie et Types Humains. Vigot Frères. Paris, pp. 90-91.

Pathmanathan G. and Prakash S. (1994) Growth of sitting height, subischial leg length and weight in well-off northwestern Indian children. Annals of Human Biology, 21: 325-334.

Research Institute of Human Engineering for Quality Life (1997) Data Book of Japanese Body Size. HQL, Osaka (in Japanese).

Schreider E. (1971) Variations morphologiques et différences climatiques. Biométrie Humaine, 6: 46-69.

Tanner J.M., Hayashi T., Preece A., and Cameron N. (1982) Increase in length of leg relative to trunk in Japanese children and adults from 1957 to 1977: comparison with British and with Japanese Americans. Annals of Human Biology, 9: 411423.

Weiner J.S. and Lourie J.A. (1981) Practical Human Biology. Academic Press, London, pp. 14-15.

Weitz C.A., Garruto R.M., Chin C., and Liu J. (2004) Morphological growth and thorax dimensions among Tibetan compared to Han children, adolescents and young adults born and raised at high altitude. Annals of Human Biology, 31: 292-310.

Zhang X. and Huang Z. (1988) The second national growth and development survey of children in China. 1985. Annals of Human Biology, 15: 289-305. 